Western University

Scholarship@Western

2019

Cognition Predicts Mobility Change in Lower Extremity Amputees

Between Discharge From Rehabilitation and 4-Month Follow-up: A

Prospective Cohort Study.

Susan W. Hunter

Pavlos Bobos

Courtney Frengopoulos

Austin Macpherson

Ricardo Viana

See next page for additional authors

Follow this and additional works at: https://ir.lib.uwo.ca/ptpub

Part of the Physical Therapy Commons 
Authors

Susan W. Hunter, Pavlos Bobos, Courtney Frengopoulos, Austin Macpherson, Ricardo Viana, and Michael W Payne 


\section{Cognition predicts mobility change in lower extremity amputees between discharge from rehabilitation and four months follow-up: A prospective cohort study}

Susan W. Hunter PT, $\mathrm{PhD}^{1,3,4}$, Pavlos Bobos PT, PhD(c) ${ }^{1,4}$, Courtney Frengopoulos $\mathrm{MSc}^{1}$, Austin Macpherson $\mathrm{HBSc}^{5}$, Ricardo Viana MD, $\mathrm{OT}^{2,3}$, Michael WC Payne MD, $\mathrm{MSc}^{2,3}$

1. Faculty of Health \& Rehabilitation Sciences, University of Western Ontario, London, ON.

2. Department of Physical Medicine and Rehabilitation, Parkwood Institute, London, ON, Canada

3. Schulich School of Medicine \& Dentistry, Department of Physical Medicine and Rehabilitation, University of Western Ontario, London, ON, Canada.

4. School of Physical Therapy, University of Western Ontario, London, ON, Canada.

5. School of Health Studies, University of Western Ontario, London, ON, Canada

Running title: Functional mobility changes in amputees

Reprints: Not available

Corresponding Author:

Dr. Susan W. Hunter University of Western Ontario

School of Physical Therapy

Room 1588, Elborn College

London, ON, Canada, N6G 1H1

Phone: 519-661-2111 ext 82754

Email: smuir4@uwo.ca

Presentations: Presentation at the Canadian Association of Physical Medicine \& Rehabilitation. Macpherson A, Frengopoulos C, Payne M, Viana R, Hunter SW. Changes in dual-task L Test scores in lower extremity amputees after discharge from inpatient rehabilitation: a prospective 
cohort study. Canadian Association of Physical Medicine \& Rehabilitation Annual Scientific Meeting. Whitehorse, Canada. May 30-June 2, 2018. (Poster presentation).

Funding: Funding: This work was supported by the St. Joseph's Healthcare Foundation

Cognitive Vitality and Brain Health Seed Funding Opportunity in London, Ontario, Canada. The funding body had no involvement in the conduct of the study.

Conflict of interest: The authors have none to report 


\section{Cognition predicts mobility change in lower extremity amputees between discharge from rehabilitation and four-months follow-up: A prospective cohort study}

\section{ABSTRACT}

Objectives: To assess: 1) the effect of task (single and dual-task), time (discharge and 4-months) and their interaction for mobility, 2) task prioritization during dual-task testing and 3) the association between cognition on change in mobility between discharge from rehabilitation and 4-months follow-up.

Design: Prospective cohort study

Setting: Rehabilitation hospital

Interventions: Not applicable

Main Outcome Measures: Gait velocity and L Test of Functional Mobility, single and dual-task (serial subtractions by threes), were the primary outcomes. Montreal Cognitive Assessment (MoCA) and Trail Making Test quantified cognition as secondary outcomes. Repeated measures analysis of variance evaluated the effects of task (single-task and dual-task) and time (discharge and 4-months follow-up) and their interaction on each outcome. A performance-resource operating characteristic graph evaluated gait and cognitive task prioritization. Multivariable linear regression evaluated the association between cognition and change in mobility over time. Results: 22 people with lower extremity amputations participated $(60.7 \pm 6.5$ years, $59 \%$ male $)$. No significant interactions between task and time were found (all p>.121) for L Test and gait velocity. The L Test single-task $(\mathrm{p}=.001)$ and dual-task $(\mathrm{p}=.004)$ improved over time. Gait velocity improved over time for both single-task and dual-task $(\mathrm{p}<.001)$. Dual-task performance was slower than single-task at each time point. The Trail Making Test B was independently 
associated with the change in dual-task L Test $(\mathrm{p}=.012)$, and single-task $(\mathrm{p}=.003)$ and dual-task $(\mathrm{p}=.006)$ gait velocity at follow-up.

Conclusions: Gait velocity and L Test single and dual-task improved over time. No significant interactions indicated the cognitive task did not differentially affect performance over time.

Lower executive function scores at discharge were independently associated with lower gains in all gait velocity and dual-task L Test outcomes at follow-up.

Key Words: amputation, cognition, outcome measures, rehabilitation

\author{
Abbreviations: \\ ABC-Activities specific Balance Confidence Scale \\ CRR-Correct response rate \\ DM- Diabetes Mellitus \\ DTC-Dual Task Cost \\ DTCcog- Dual-Task Cognition Cost \\ DTCgait- Dual-Task Gait Cost \\ LLA- Lower limb amputation \\ MoCA- Montreal Cognitive Assessment \\ TMT- Trail Making Test \\ PVD- Peripheral Vascular Disease
}




\section{INTRODUCTION}

In Canada, $87 \%$ of amputations are attributed to diabetic complications that occur in a predominately older adult (> 65 years) population. ${ }^{1}$ A recent Canadian study found the ageadjusted incidence rates for lower limb amputation (LLA) have decreased, but the absolute number of new LLAs has increased due to the increasing older population. ${ }^{2}$ The combination of diabetes and predominance of older adults places this patient group at a high risk of developing cognitive dysfunction ${ }^{3}$, particularly in the areas of problem-solving, reasoning and concentration. ${ }^{4}$ Impairment in cognition affects balance ${ }^{5}$ and functional mobility ${ }^{6}$ for LLAs using a prosthesis. While a prosthesis may assist with mobility, the process of learning to use a prosthesis can be cognitively challenging. ${ }^{7}$

The inter-relationship between cognition and gait can be assessed observing people walking while they simultaneously perform another task; the dual-task paradigm. ${ }^{8}$ The difference in performance between single and dual-task conditions is a measure of an individual's ability to allocate attentional resources between the two simultaneous tasks. ${ }^{8}$ When attentional resources are overloaded, performance on one or both tasks may deteriorate. ${ }^{9}$ This is referred to as the dual-task cost (DTC). ${ }^{8}$ Dual-task testing is relevant as many daily activities require the simultaneous performance of two or more tasks - often cognitive and motor tasks in combination. ${ }^{10}$

Recovery of functional mobility and improvement of activity levels are major rehabilitation goals following LLA. ${ }^{11}$ Mobility with a prosthesis has been found to significantly improve until around 6 months after discharge from rehabilitation when performance plateaus. ${ }^{12}$ Ongoing gait difficulties are a concern as this is related to an increased falls risk. ${ }^{13}$ The relationship between cognition and gait is not well understood, though $40.9 \%$ of established 
ambulators with a prosthesis report a need to concentrate on each step they take. ${ }^{14}$ Measures of functional mobility are important in providing information about post-rehabilitation mobility trajectories and independence that are linked to quality of life. ${ }^{15}$

Impaired global cognitive function is associated with lower mobility scores in LLAs after an inpatient prosthetic rehabilitation program. ${ }^{6,16,17}$ New and established prosthetic ambulators have demonstrated similar performance and task prioritization under dual-task conditions. ${ }^{18}$ Specifically, both gait and cognitive task performance deteriorate in dual-task testing, but the majority of people prioritized the gait task for a posture-first strategy. ${ }^{18}$ While cross-sectional findings provide insight about mobility and cognition there has been no prospective investigation directly quantifying the cognitive-motor inter-relationship over time in LLAs.

Therefore, the study objectives were: 1 ) to assess the effect of task (single and dualtask), time (discharge and 4-months) and their interaction for L Test of Functional Mobility and gait velocity, 2) to assess task prioritization during dual-task testing, and 3) to investigate the association between cognitive function on change in mobility between discharge from rehabilitation and 4-months follow-up for patients with unilateral trans-femoral or trans-tibial amputations. It was hypothesized performance will improve on all mobility tests at follow-up and lower cognitive scores will be associated with lower change in mobility after discharge.

\section{METHODS}

\section{Study Design}

This was a prospective cohort study of consecutive admissions to the regional inpatient amputee rehabilitation program at Parkwood Institute in London, Ontario, Canada. Data were collected between April 2016 and September 2017. This study was approved by Health Sciences 
Research Ethics Boards at the University of Western Ontario and by the Clinical Resources Impact Committee of Lawson Health Research Institute in London, Ontario, Canada.

\section{Participants}

Admission criteria for the inpatient amputee rehabilitation program were: age 18 years of age or older, had identifiable rehabilitation goals, was medically stable, and was mentally and physically ready to enter the comprehensive rehabilitation program. Individuals admitted to the inpatient amputee rehabilitation program are admitted from home after the incision has healed. Study eligibility criteria were: 50 years of age or older, first major unilateral lower limb amputation (trans-tibial or trans-femoral), able to walk at least 10m without the assistance of another person (mobility aid use permitted), and a functional use of the English language. Participants who had any prior neurological disorder or physical problem that limited their walking ability were excluded from the study. All participants provided written informed consent.

\section{Data collection}

The following demographic and medical information were obtained: age, sex, height, weight, BMI $\left(\mathrm{kg} / \mathrm{m}^{2}\right)$, years of education, type and level of amputation, amputation etiology and falls history. Global cognition was measured at admission to rehabilitation using the Montreal Cognitive Assessment (MoCA) ${ }^{19}$ and the Trail Making Test (TMT) was performed 48 hours prior to discharge. Balance confidence was measured within 48 hours of discharge with the Activities-specific Balance Confidence Scale (ABC). ${ }^{20}$ The single and dual-task L Test of Functional Mobility, single and dual-task gait velocity, and a single-task cognitive assessment were administered at discharge and 4-months follow-up. (Described in outcome measures below) Assessments were completed in the same order for all participants, with a 5 minute rest provided 
between each of the mobility assessments. The return assessment occurred at their regularly scheduled medical visit 4-months after discharge.

\section{Outcome Measures}

Cognition: Cognitive function was evaluated using the MoCA and the Trail Making Test (TMT). The MoCA has a maximum score of 30 , with scores $\leq 25$ indicative of mild impairment in cognition. ${ }^{19}$ The TMT has two parts, Part A (TMT-A) assesses visual attention and cognitive speed skills whereas Part B (TMT-B) evaluates higher-order cognitive skills such as working

memory and task-shifting/attention, considered a measure of executive functioning. ${ }^{21}$ Results are reported as the time required to complete the task to the nearest $100^{\text {th }}$ of a second; a longer completion time indicates greater impairment.

Single-Task Cognitive Assessment: The cognitive task of serial subtractions by threes, starting at 100 , was performed in a seated position prior to the mobility tests. Time to complete 18 subtractions was recorded to the nearest $100^{\text {th }}$ of a second with a stop watch. The responses and number of correct responses given were recorded. ${ }^{22}$

L Test of Functional Mobility: The L Test of Functional Mobility (L Test) assesses functional mobility in the LLA population. As per standard instruction, participants began from a sitting position, and upon the word "go" rose to standing and walked three meters, turned $90^{\circ}$, walked seven meters, turned $180^{\circ}$, and walked along the same L-shaped path to return to a seated position. ${ }^{23}$ The test was performed at their usual comfortable pace. A dual-task version of the $\mathrm{L}$ Test using serial subtractions by threes was also performed according to the protocol described in Hunter et al. 2017. ${ }^{22}$ L Test times were recorded to the nearest $100^{\text {th }}$ of a second with a stop watch and cognitive responses were recorded. Individuals were given no instructions on task prioritization. The minimum detectable change (MDC) for the single-task L Test is MDC $=3.19$ 
sec and for the dual-task L Test is MDC=3.76 sec for trans-tibial amputation of vascular etiology. ${ }^{22}$

Gait Velocity: Gait velocity was measured using the GAITRite® System, an instrumented walkway measuring 6 meters by 0.64 meters. A one-meter distance before and after the boundaries of the walkway was used to account for acceleration and deceleration, which was not incorporated into the collected data. Gait velocity at usual comfortable pace was measured in centimeters per second, making larger velocity scores indicative of better physical functioning. Gait testing was performed as a single and dual-task protocol, where the dual-task protocol used serial subtractions by threes as described previously. Responses on the secondary cognitive task were recorded. No instructions on task prioritization were given. The MDC of 0.04 to $0.06 \mathrm{~m} / \mathrm{s}$ was used to evaluate velocity scores. ${ }^{24}$

\section{Statistical Analysis}

Descriptive statistics using means and SDs or frequency and percentages were calculated to describe the demographic and clinical characteristics of the sample. To address objective 1, the effect of single and dual-task performance on mobility (L Test and gait velocity), changes in gait measures over time (discharge and follow-up) and the interaction of these two factors (task and time) we conducted repeated measures analyses of variance (ANOVA-RM). Cohen's d effect size (ES) quantified the magnitude of the difference in the paired comparisons. Benchmark values for ES to estimate the magnitude of the effect and classified were: trivial $(<0.20)$, small $(<0.20$ to $<0.50)$, moderate $(<0.50$ to $<0.80)$ or large $(<0.80) .{ }^{25}$

To evaluate task prioritization, a performance-resource operating characteristic (POC) graph was created by plotting dual-task cost for cognitive task (DTC cog) on the x-axis versus dual-task gait cost (DTCgait) on the y-axis for L Test and gait velocity. ${ }^{8}$ The dual-task cost is the 
ratio of change in gait or cognitive performance on the dual-task test relative to the single-task condition. ${ }^{21,26,27}$ The DTCgait was calculated as:

$$
\text { DTCgait }=\frac{(\text { single-task test- } \text { dual-task test })}{\text { single-task test }} \times 100 \%
$$

Cognitive performance was determined by first calculating the correct response rate (CRR) for the single-task cognitive test and dual-task tests (L Test and gait velocity) as: (Response rate per second $X$ percent correct). ${ }^{28} \mathrm{CRR}$ accounts for speed and accuracy of responses given. ${ }^{28}$ DTC $\operatorname{cog}$ was calculated as:

$\mathrm{DTC}_{\operatorname{cog}}=(-1)\left(C R R_{\text {serial-subtractions:seated-CRR }}\right.$ serial-subtractions:walk $) \times 100 \%$ $C R R_{\text {serialsubtractions:seated }}$

The interpretation of the dual-task cost value is the same for both DTCgait and DTCcog. A negative value indicates poorer performance under dual-task conditions (i.e., longer walking time under the dual-task condition). A positive value indicates better performance under dualtask conditions (i.e., shorter walking time). In the POC curve, performance will fall into one of four quadrants: (1) upper left - improvement of gait with worsening of cognitive task, (2) upper right - improvement of gait with improvement of cognitive task, (3) lower left - worsening of gait with worsening of cognitive task, (4) lower right - worsening of gait with improvement of cognitive task. Performance that falls on the axes at $0 \%$ DTC for gait and cognition indicates no change in performance between single- and dual-task conditions. ${ }^{18}$ A diagonal line through quadrants two and three indicates a 1:1 trade off during dual-task performance; to the left of this line gait is prioritized and to the right the cognitive task is prioritized. ${ }^{8}$

To address the third objective, multivariable linear regression modeling evaluated the association of cognition (MoCA, TMT-A, TMT-B scores) on the change in mobility between discharge and 4-months after discharge. The dependent variable was the 4-months mobility 
score. Regression modelling was adjusted on baseline mobility score, age, Activity-specific Balance Confidence score and etiology of amputation. Statistical significance was set at $p<.05$. Data were analyzed using SPSS (Version 25.0; SPSS Inc, Chicago IL).

\section{RESULTS}

\section{Demographics}

Thirty individuals were enrolled in the study, 22 completed all mobility assessments. Follow-up assessments were incomplete for the following reasons: non-ambulatory (2), deceased (1), stopped wearing the prosthesis (1), testing problems (2), lost to follow-up (1), and unable to return due to family emergency (1). Overall, the 22 participants had a mean age of $60.7 \pm 6.5$ years and $59 \%$ were male. (Table 1)

\section{Mobility Changes}

\section{Test}

The interaction between task $\mathrm{x}$ time was not statistically significant, indicating the cognitive task did not differentially affect performance between baseline and 4-months. The main effects were statistically significant for task ( $\mathrm{p}<.001)$ and time $(\mathrm{p}=.001)$. (Table 2) Singletask L Test scores demonstrated that time to complete the test was shorter at 4-months follow-up. The single-task L Test improved for 20 (90.9\%) people and this improvement exceeded the MDC value for $17(81 \%)$. Dual-task L Test scores also demonstrated the time to complete the test improved over time. The dual-task L Test improved for 20 (90.9\%) participants between discharge and 4-months follow-up. The improvement for 17 (85\%) exceeded the MDC value. Performance on the dual-task L Test was statistically significantly slower than the single-task condition at each time point.

\section{Gait Velocity}


The interaction between task $\mathrm{x}$ time was not statistically significant, indicating the cognitive task did not differentially affect performance between discharge and 4-months. The main effects of task (.009) and time (p=.002) were statistically significant. (Table 3) Single-task and dual-task velocity improved over time with people walking at a faster pace at 4-months. These changes in the dual-task testing exceeded the MDC values for $19(87 \%)$ individuals.

Performance on the dual-task test resulted in a statistically significantly slower gait velocity than the single-task condition at each time point.

\section{Performance Operating Characteristic (POC)}

In the L Test, the gait and cognitive tasks were negatively impacted by dual-task testing at both time points. While both tasks deteriorated in the dual-task testing, the trade-off between the tasks indicated the majority of the participants prioritized the gait task over the cognitive task at discharge and 4-months follow-up. Visual inspection would support a stable prioritization of tasks at both time points.

For gait velocity, in contrast to the L Test results, there was a prioritization of the cognitive task over gait performance at discharge and the 4-months follow-up. Visually, there was an increase in the prioritization of the cognitive task at 4-months. (Figure 1 and 2)

\section{Association of cognition with mobility function 4-months after discharge}

TMT-B was associated with the change in single-task $(\mathrm{p}=.003)$ and dual-task $(\mathrm{p}=.006)$ gait velocity, and dual-task L Test (p=.012). (Table 4) Increased time to complete the TMT-B, representing greater cognitive impairment, was associated with requiring more time to complete the L Test and slower velocity. Specifically, we found that for every 1 second increase in TMT-B scores, the change in single-task and dual-task gait velocity was reduced by $1.12 \mathrm{~cm} / \mathrm{s}$ and 0.88 $\mathrm{cm} / \mathrm{sec}$, respectively. 


\section{DISCUSSION}

This study has demonstrated that mobility, both the single and dual-task tests, significantly increased between discharge and 4-months after prosthetic rehabilitation. Importantly, the cognitive task did not appear to differentially impact performance over time. Lower cognitive function scores on the Trail Making Test B, which combines visual scanning, motor speed and alternating attention/working memory, were associated with lower functional gains 4-months after discharge from rehabilitation. This study provides novel information on the cognitive-motor inter-relationship after discharge from prosthetic rehabilitation.

Our study supports previous findings of a connection between functional mobility and cognition. ${ }^{4,5}$ Importantly, the recent review by Morgan et al.$^{29}$ highlighted the limited existing literature on dual-task testing in amputees and the lack of prospective studies evaluating change over time. Our study adds novel information with direct quantification of the cognitive-motor inter-relationship over time. Understanding the role of cognition in the initial months after the rehabilitation process is important, as Coffey et al. ${ }^{4}$ found cognitive deficits result in significant difficulties in learning how to use a prosthesis and in regaining mobility and independence in activities of daily living following LLA. O’Neill and Evans ${ }^{6}$ found executive function, using a test of verbal fluency, was associated with less extensive use of the prosthesis 6-months after discharge from rehabilitation. Our study builds upon the existing research, demonstrating the TMT-B at discharge is associated with dual-task L Test and, single and dual-task gait velocity at 4-months after discharge. Our study supports the need for research into the evaluation of cognitive and physical exercises during rehabilitation, a treatment that has been suggested for other cognitively-impaired populations. ${ }^{30}$ 
Another novel finding was the evaluation of gait and cognitive task prioritization during the dual-task testing over time. We found gait performance was prioritized for the L Test and gait velocity at discharge and remained the salient task for the L Test, a more complex activity, at 4-months. In those with functional limitations (e.g., a walking impairment), greater attentional demand is needed when walking to accommodate for a less stable system and therefore gait is expected to be prioritized over competing tasks, called a posture-first strategy. ${ }^{10}$ Cognitive demands also vary with task complexity, such that walking in a complex path requires greater cognitive resources than a straight path. ${ }^{31}$ This study's findings are consistent with the posturefirst strategy being used at both time points for the more complex task, the L Test, as the gait task was prioritized over the cognitive task.

In our study though mobility improved over time, the cognitive demands of ambulating with a prosthesis did not change. Our findings are consistent with the results of Frengopoulos et al. ${ }^{18}$ who found the cognitive demands during walking were similar between new and experienced trans-tibial amputees using a prosthesis. Conversely, Geurts et al. ${ }^{32}$ found the cognitive load in static balance positions improved with rehabilitation and suggested this was due to central neural adaptation of the new postural requirements. Yet, even years after successful completion of prosthetic rehabilitation, $40.9 \%$ of LLAs report having to concentrate on every step they take when ambulating with their prosthesis. ${ }^{14}$ Gait is a more complex activity than static balance, requiring greater cognitive resources to successfully adapt walking patterns to avoid or negotiate obstacles, changing direction and planning a path. A limb amputation leads to changes in muscle activity, joint mobility and sensory input to the brain that may not be fully compensated with learning new movement patterns to walk with a prosthesis resulting in fixed greater cognitive demands. ${ }^{7,33}$ An exciting area of emerging research in cognitive-motor effects 
is the role of the prosthesis. Morgan et al. ${ }^{34}$ found a concurrent cognitive task resulted in a similar response to the cognitive demands between age and sex-matched controls and persons with trans-femoral amputations using a prosthesis with a microprocessor knee.

\section{Limitations}

This study has several limitations that should be considered. Twenty-seven percent of the sample was not able to contribute mobility data at follow-up and therefore the study may not have been powered enough to find associations. To offset the small sample size, we calculated effect sizes to indicate the magnitude of the effects and compared results to established minimum different change scores. We were also not able to stratify the group to explore interesting clinical features, such as level of amputation. Future studies should employ short and long-term followups to better examine long-term change in functioning. In terms of strengths, all people who met the inclusion criteria during the study time frame were enrolled and therefore this study is representative of the patient population seen at this institution. Valid and reliable measures for the assessment of the cognitive-motor inter-relationship were used and we directly evaluated task prioritization during dual-task testing.

\section{CONCLUSIONS}

People with LLAs demonstrated significant improvements in single-task and dual-task gait velocity and $\mathrm{L}$ Test after discharge. Lower scores on measures of cognitive function were associated with smaller gains in functional mobility after discharge, though ninety percent of the sample demonstrated gains that were in excess of the minimal detectable change for both gait velocity and L Test. Prospective studies over a longer duration with a larger sample are warranted to monitor ongoing changes between cognition and mobility, along with risk for adverse events such as falls. 


\section{REFERENCES}

1. Kayssi A, de Mestral C, Forbes TL, Roche-Nagle G. A Canadian population-based description of the indications for lower-extremity amputations and outcomes. Can. J. Surg. 2016;59:99-106.

2. Imam B, Miller WC, Finlayson HC, Eng JJ, Jarus T. Incidence of lower limb amputation in Canada. Can. J. Public Heal. 2017;108:e374-80.

3. McCrimmon RJR, Ryan CMC, Frier BBM. Diabetes and cognitive dysfunction. Lancet. 2012;379:2291-9.

4. Coffey L, O'Keeffe F, Gallagher P, Desmond D, Lombard-Vance R, O'Keeffe F, et al. Cognitive functioning in persons with lower limb amputations: a review. Disabil. Rehabil. [Internet]. 2012;34:1950-64. Available from: http://www.tandfonline.com/doi/full/10.3109/09638288.2012.667190

5. Frengopoulos C, Burley J, Viana R, Payne MW, Hunter SW. Association Between Montreal Cognitive Assessment Scores and Measures of Functional Mobility in Lower Extremity Amputees After Inpatient Rehabilitation. Arch. Phys. Med. Rehabil. 2017;98:450-5.

6. O’Neill BF, Evans JJ. Memory and executive function predict mobility rehabilitation outcome after lower-limb amputation. Disabil. Rehabil. 2009;31:1083-91.

7. Vrieling AH, van Keeken HG, Schoppen T, Otten E, Hof AL, Halbertsma JPKK, et al. Balance control on a moving platform in unilateral lower limb amputees. Gait Posture. 2008;28:222-8.

8. McIsaac TL, Lamberg EM, Muratori LM. Building a framework for a dual task taxonomy. Biomed Res. Int. 2015;2015:591475. 
9. Yogev-Seligmann G, Hausdorff JM, Giladi N. The role of executive function and attention in gait. Mov. Disord. [Internet]. 2008;23:329-42. Available from: http://doi.wiley.com/10.1002/mds.21720

10. Woollacott M, Shumway-Cook A. Attention and the control of posture and gait: A review of an emerging area of research. Gait Posture. 2002;16:1-14.

11. Deathe AB, Wolfe DL, Devlin M, Hebert JS, Miller WC, Pallaveshi L. Selection of outcome measures in lower extremity amputation rehabilitation: ICF activities. Disabil. Rehabil. [Internet]. 2009;31:1455-73. Available from:

http://www.tandfonline.com/doi/full/10.1080/09638280802639491\%5Cnhttp://search.ebsc ohost.com/login. aspx $?$ direct $=$ true $\& d b=c 8 h \& A N=2010378654 \&$ site=ehost-live

12. Czerniecki JM, Turner AP, Williams RM, Hakimi KN, Norvell DC. Mobility changes in individuals with dysvascular amputation from the presurgical period to 12 months postamputation. Arch. Phys. Med. Rehabil. [Internet]. 2012;93:1766-73. Available from: http://dx.doi.org/10.1016/j.apmr.2012.04.011

13. Hunter SW, Batchelor F, Hill KD, Hill A-M, Mackintosh S, Payne M. Risk Factors for Falls in People With a Lower Limb Amputation: A Systematic Review. Phys. Med. Rehabil. 2017;9:170-80.

14. Miller WC, Deathe AB, Speechley M, Koval J. The influence of falling, fear of falling, and balance confidence on prosthetic mobility and social activity among individuals with a lower extremity amputation. Arch. Phys. Med. Rehabil. [Internet]. 2001;82:1238-44. Available from: http://linkinghub.elsevier.com/retrieve/pii/S0003999301150264

15. Cox PD, Frengopoulos CA, Hunter SW, Sealy CM, Deathe AB, Payne MWC. Impact of Course Configuration on 6-Minute Walk Test Performance of People with Lower 
Extremity Amputations. Physiother. Canada. 2017;69:197-203.

16. Frengopoulos C, Burley J, Viana R, Payne M, Hunter S. Association between MoCA scores and functional outcomes after inpatient rehabilitation for a lower extremity prosthesis. Arch. Phys. Med. Rehabil. 2016;doi: 10.1016/j.apmr.2016.06.012.

17. Williams RM, Turner AP, Green M, Norvell DC, Henderson AW, Hakimi KN, et al. Relationship between cognition and functional outcomes after dysvascular lower extremity amputation: A prospective study. Am. J. Phys. Med. Rehabil. [Internet]. 2015;94:707-17. Available from: http://content.wkhealth.com/linkback/openurl?sid=WKPTLP:landingpage\&an=00002060900000000-99175

18. Frengopoulos C, Payne MW, Holmes JD, Viana R, Hunter SW. Comparing the Effects of Dual-task Gait Testing in New and Established Ambulators with Lower Extremity Amputations. PM\&R [Internet]. 2018;10:1012-9. Available from: http://linkinghub.elsevier.com/retrieve/pii/S1934148218301758

19. Nasreddine ZS, Phillips N a., Bedirian V, Charbonneau S, Whitehead V, Collin I, et al. The Montreal Cognitive Assessment, MoCA: A Brief Screening Tool for Mild Cognitive Impairment. J. Am. Geriatr. Soc. 2005;53:695-9.

20. Miller WC, Deathe AB, Speechley M. Psychometric properties of the activities-specific balance confidence scale among individuals with a lower-limb amputation. Arch. Phys. Med. Rehabil. [Internet]. 2003;84:as0003999303048074. Available from: http://www.mosby.com/scripts/om.dll/serve?action=searchDB\&searchDBfor=art\&artTyp e=abs\&id=as0003999303048074

21. Montero-Odasso M, Almeida QJ, Bherer L, Burhan AM, Camicioli R, Doyon J, et al. 
Consensus on Shared Measures of Mobility and Cognition: From the Canadian

Consortium on Neurodegeneration in Aging (CCNA). Journals Gerontol. Ser. A [Internet].

2018;XX:1-13. Available from: https://academic.oup.com/biomedgerontology/advancearticle/doi/10.1093/gerona/gly148/5042781

22. Hunter SW, Frengopoulos C, Holmes J, Viana R, Payne MW. Determining Reliability of a Dual-Task Functional Mobility Protocol for Individuals With Lower Extremity Amputation. Arch. Phys. Med. Rehabil. 2018;99:707-12.

23. Deathe AB, Miller WCW. the L test of functional mobility: measurement properties of a modified version of the timed "up \& go" test designed for people with lower-limb amputations. Phys. Ther. 2005;85:626-35.

24. Perera S, Mody SH, Woodman RC, Studenski SA. Meaningful Change and Responsiveness in Common Physical Performance Measures in Older Adults. J. Am. Geriatr. Soc. [Internet]. 2006;54:743-9. Available from: http://doi.wiley.com/10.1111/j.1532-5415.2006.00701.x

25. Cohen J. Statistical power analysis for the behavioral sciences. Stat. Power Anal. Behav. Sci. 1988;

26. Al-Yahya E, Dawes H, Smith L, Dennis A, Howells K, Cockburn J. Cognitive motor interference while walking: A systematic review and meta-analysis. Neurosci. Biobehav. Rev. [Internet]. 2011;35:715-28. Available from: http://dx.doi.org/10.1016/j.neubiorev.2010.08.008

27. Montero-Odasso M, Oteng-Amoako A, Speechley M, Gopaul K, Beauchet O, Annweiler C, et al. The Motor Signature of Mild Cognitive Impairment: Results From the Gait and Brain Study. Journals Gerontol. Ser. A Biol. Sci. Med. Sci. [Internet]. 2014;69:1415-21. 
Available from:

http://biomedgerontology.oxfordjournals.org/cgi/doi/10.1093/gerona/glu155

28. Hall CD, Echt K V, Wolf SL, Rogers WA. Cognitive and motor mechanisms underlying older adults' ability to divide attention while walking. Phys. Ther. [Internet]. 2011;91:1039-50. Available from:

https://academic.oup.com/biomedgerontology/advancearticle/doi/10.1093/gerona/gly148/5042781

29. Morgan SJ, Hafner BJ, Kartin D, Kelly VE. Dual-task standing and walking in people with lower limb amputation: A structured review. Prosthet. Orthot. Int. [Internet]. 2018;030936461878572. Available from:

http://journals.sagepub.com/doi/10.1177/0309364618785728

30. Montero-Odasso M, Verghese J, Beauchet O, Hausdorff JM. Gait and Cognition: A Complementary Approach to Understanding Brain Function and the Risk of Falling. J. Am. Geriatr. Soc. [Internet]. 2012;60:2127-36. Available from: http://doi.wiley.com/10.1111/j.1532-5415.2012.04209.x

31. Lowry KA, Brach JS, Nebes RD, Studenski SA, VanSwearingen JM. Contributions of Cognitive Function to Straight- and Curved-Path Walking in Older Adults. Arch. Phys. Med. Rehabil. [Internet]. 2012;93:802-7. Available from: http://linkinghub.elsevier.com/retrieve/pii/S0003999311011026

32. Geurts AC, Mulder TW, Nienhuis B, Eng M, Rijken RA. Dual-Task Assessment of Reorganization of Postural Control in Persons with Lower Limb Amputation.

33. Ku PX, Abu Osman NA, Wan Abas WAB. Balance control in lower extremity amputees during quiet standing: A systematic review. Gait Posture [Internet]. 2014;39:672-82. 
Available from: http://dx.doi.org/10.1016/j.gaitpost.2013.07.006

34. Morgan SJ, Hafner BJ, Kelly VE. The effects of a concurrent task on walking in persons with transfemoral amputation compared to persons without limb loss. Prosthet. Orthot. Int. 2016;40:490-6. 
Table 1. Demographic and clinical characteristics of a cohort of adults with lower limb amputation at discharge from prosthetic rehabilitation. $(n=22)$

\begin{tabular}{|c|c|}
\hline Characteristic & Mean \pm SD or frequency $(\%)$ \\
\hline Age (years) & $60.7 \pm 6.5$ \\
\hline $\operatorname{Sex}(\mathrm{n}, \%$ males $)$ & $13(59.0 \%)$ \\
\hline Height $(\mathrm{cm})$ & $173.4 \pm 11.1$ \\
\hline Weight (kg) & $88.7 \pm 23.7$ \\
\hline Body Mass Index (kg/m2) & $29.3 \pm 6.6$ \\
\hline Years of Education & $13.0 \pm 2.0$ \\
\hline Activities-specific Balance Confidence Scale (\%) & $67.7 \pm 14.7$ \\
\hline Montreal Cognitive Assessment score & $26.1 \pm 2.5$ \\
\hline Level of amputation is trans-tibial & $19(86.4 \%)$ \\
\hline \multicolumn{2}{|l|}{ Primary Etiology of Amputation: } \\
\hline -Diabetes Mellitus & $15(68.2 \%)$ \\
\hline -Peripheral Vascular Disease & $2(9.1 \%)$ \\
\hline -Diabetes Mellitus and Peripheral Vascular Disease & $1(4.6 \%)$ \\
\hline -Cancer & $1(4.6 \%)$ \\
\hline -Other & $3(13.6 \%)$ \\
\hline
\end{tabular}

Note: SD, standard deviation. 
Table 2. Evaluation of task, time and their interaction in L Test between discharge from inpatient prosthetic rehabilitation and 4-months follow-up for a cohort of lower limb amputees. $(n=22)$

\begin{tabular}{|c|c|c|c|c|}
\hline & Time $(n$ & $\operatorname{an} \pm$ SD) & & \\
\hline Task & Discharge & $\begin{array}{l}\text { 4-months } \\
\text { Follow-up }\end{array}$ & $\begin{array}{l}\text { Paired comparison } \\
\text { and ES for time }\end{array}$ & $\begin{array}{c}\text { Overall } \\
\text { Repeated } \\
\text { Measures } \\
\text { ANOVA }\end{array}$ \\
\hline $\begin{array}{c}\text { Single-task test } \\
\text { (seconds) }\end{array}$ & 74.96 (50.68) & $52.40(38.53)$ & $\mathrm{p}=.001, \mathrm{ES}=0.50$ & $\begin{array}{l}\text { task } \mathrm{p}<.001 \\
\text { time } \mathrm{p}=.001\end{array}$ \\
\hline $\begin{array}{c}\text { Dual-task test } \\
\text { (seconds) }\end{array}$ & $93.90(73.80)$ & 60.54 (42.99) & $\mathrm{p}=.004, \mathrm{ES}=0.55$ & $\begin{array}{l}\text { task } \mathrm{x} \text { time } \\
\mathrm{p}=.552\end{array}$ \\
\hline $\begin{array}{l}\text { Paired comparison } \\
\text { and ES for task }\end{array}$ & $\begin{array}{l}\mathrm{p}=.023, \\
\mathrm{ES}=0.29\end{array}$ & $\begin{array}{l}\mathrm{p}=.001, \\
\mathrm{ES}=0.19\end{array}$ & & \\
\hline
\end{tabular}

ES, Cohen's d effect size for the magnitude of the difference in the paired comparisons. Benchmark values for ES the magnitude of the effect were: trivial $(<0.20)$, small $(<0.20$ to $<0.50)$, moderate $(<0.50$ to $<0.80)$ or large $(<0.80){ }^{28}$ 
Table 3. Evaluation of task, time and their interaction in gait velocity between discharge from inpatient prosthetic rehabilitation and 4-months follow-up for a cohort of lower limb amputees. $(n=22)$

\begin{tabular}{|c|c|c|c|c|}
\hline & Time (n & $\mathrm{an} \pm$ SD) & & \\
\hline Task & Discharge & $\begin{array}{l}\text { 4-months } \\
\text { Follow-up }\end{array}$ & $\begin{array}{l}\text { Paired comparison } \\
\text { and ES for time }\end{array}$ & $\begin{array}{c}\text { Overall } \\
\text { Repeated } \\
\text { Measures } \\
\text { ANOVA }\end{array}$ \\
\hline $\begin{array}{c}\text { Single-task test } \\
(\mathrm{cm} / \mathrm{s})\end{array}$ & 54.89 (26.53) & $71.86(25.81)$ & $\mathrm{p}<.001, \mathrm{ES}=0.64$ & $\begin{array}{l}\text { task } \mathrm{p}<.002 \\
\text { time } \mathrm{p}=.009\end{array}$ \\
\hline $\begin{array}{c}\text { Dual-task test } \\
(\mathrm{cm} / \mathrm{s})\end{array}$ & 44.97 (24.68) & $62.28(28.62)$ & $\mathrm{p}<.001, \mathrm{ES}=0.64$ & $\begin{array}{l}\text { task } \mathrm{x} \text { time } \\
\mathrm{p}=.121\end{array}$ \\
\hline $\begin{array}{l}\text { Paired comparison } \\
\text { and ES for task }\end{array}$ & $\begin{array}{c}\mathrm{p}=.003, \\
\mathrm{ES}=0.38\end{array}$ & $\begin{array}{c}\mathrm{p}=.017, \\
\mathrm{ES}=0.35\end{array}$ & & \\
\hline
\end{tabular}

ES, Cohen's d effect size for the magnitude of the difference in the paired comparisons. Benchmark values for ES of the magnitude of the effect were: trivial $(<0.20)$, small $(<0.20$ to $<0.50)$, moderate $(<0.50$ to $<0.80)$ or large $(<0.80){ }^{28}$ 
Table 4. Results of multivariable linear regression modelling for the association of Montreal Cognitive Assessment and Trail Making Tests A and B scores at discharge on measures of mobility at 4 months after discharge from inpatient prosthetic rehabilitation.

\begin{tabular}{|c|c|c|c|c|c|}
\hline Cognitive Test & Outcome & $\begin{array}{c}\text { Unadjusted } \\
\text { Unstandardized } \\
\text { 及 (95\% CI) }\end{array}$ & $\begin{array}{c}\text { P } \\
\text { value }\end{array}$ & $\begin{array}{c}\text { Adjusted } \\
\text { Unstandardized } \\
\beta(95 \% \mathrm{CI})^{*}\end{array}$ & $\begin{array}{c}\text { p- } \\
\text { value }\end{array}$ \\
\hline $\begin{array}{l}\text { Montreal } \\
\text { Cognitive }\end{array}$ & $\begin{array}{l}\text { L Test -Single- } \\
\text { Task }\end{array}$ & $\begin{array}{l}-0.03(-0.05, \\
0.004)\end{array}$ & .087 & $0.01(-0.04,0.07)$ & .569 \\
\hline \multirow[t]{3}{*}{ Assessment } & $\begin{array}{l}\text { L Test- Dual- } \\
\text { Task }\end{array}$ & $\begin{array}{l}-0.03(-0.05, \\
0.002)\end{array}$ & .035 & $\begin{array}{l}-0.005(-0.05, \\
0.04)\end{array}$ & .809 \\
\hline & $\begin{array}{l}\text { Gait Velocity - } \\
\text { Single-Task }\end{array}$ & $0.05(0.01,0.09)$ & .015 & $0.04(-0.06,0.13)$ & .420 \\
\hline & $\begin{array}{l}\text { Gait Velocity - } \\
\text { Dual-Task }\end{array}$ & $0.06(0.03,0.09)$ & .001 & $0.06(-0.01,0.14)$ & .099 \\
\hline \multirow[t]{4}{*}{$\begin{array}{l}\text { Trail Making } \\
\text { Test - Part A }\end{array}$} & $\begin{array}{l}\text { L Test - Single- } \\
\text { Task }\end{array}$ & $0.21(0.03,0.40)$ & .026 & $0.21(-0.13,0.54)$ & .212 \\
\hline & $\begin{array}{l}\text { L Test - Dual- } \\
\text { Task }\end{array}$ & $0.18(0.01,0.35)$ & .044 & $0.16(-0.13,0.45)$ & .248 \\
\hline & $\begin{array}{l}\text { Gait Velocity - } \\
\text { Single-Task }\end{array}$ & $\begin{array}{l}-0.33(-0.59,- \\
0.07)\end{array}$ & .016 & $\begin{array}{l}-0.23(-0.65, \\
0.19)\end{array}$ & .266 \\
\hline & $\begin{array}{l}\text { Gait Velocity - } \\
\text { Dual-Task }\end{array}$ & $\begin{array}{l}-0.26(-0.50,- \\
0.02)\end{array}$ & .036 & $\begin{array}{l}-0.15(-0.53, \\
0.22)\end{array}$ & .397 \\
\hline
\end{tabular}




\begin{tabular}{|l|l|l|l|l|l|}
\hline Trail Making & L Test - Single- & $0.49(0.17,0.81)$ & $\mathbf{. 0 0 5}$ & $0.58(-0.03,1.19)$ & .060 \\
& Task & & & & \\
\cline { 2 - 6 } & L Test - Dual- & $0.47(0.19,0.74)$ & $\mathbf{. 0 0 2}$ & $0.64(0.16,1.12)$ & $\mathbf{. 0 1 2}$ \\
& Task & & & & \\
\cline { 2 - 6 } & Gait Velocity - & $-0.99(-1.35,-$ & $\mathbf{. 0 0 0}$ & $-1.12(-1.80,-$ & $\mathbf{. 0 0 3}$ \\
& Single-Task & $0.64)$ & & $0.45)$ & \\
\cline { 2 - 6 } & Gait Velocity - & $-0.91(-1.32,-$ & $\mathbf{. 0 0 0}$ & $-0.88(-1.47,-$ & $\mathbf{. 0 0 6}$ \\
\hline
\end{tabular}

Note: $\beta=$ standardized regression coefficient; $\mathrm{CI}=$ confidence interval; $*$, variables adjusted for in the regression modeling were baseline mobility score, age, Activity-specific Balance Confidence score and etiology of amputation. 


\section{Figure Legends}

Figure 1. Performance-resource operating characteristic (POC) graph for cognition-gait interaction in the dual-task L Test.

Figure 2. Performance-resource operating characteristic (POC) graph for cognition-gait interaction in the gait velocity. 
Figure 1. Performance-resource operating characteristic (POC) graph for cognition-gait interaction in the dual-task L Test.

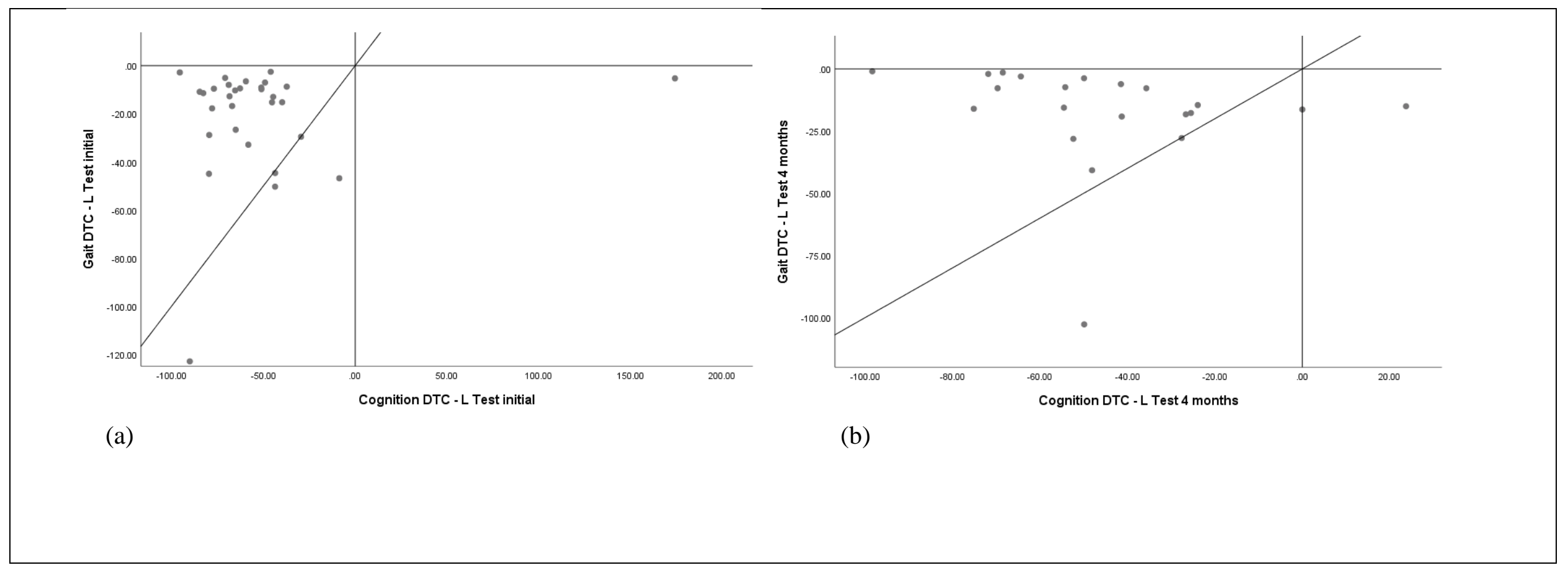


Figure 2. Performance-resource operating characteristic (POC) graph for cognition-gait interaction in the gait velocity.

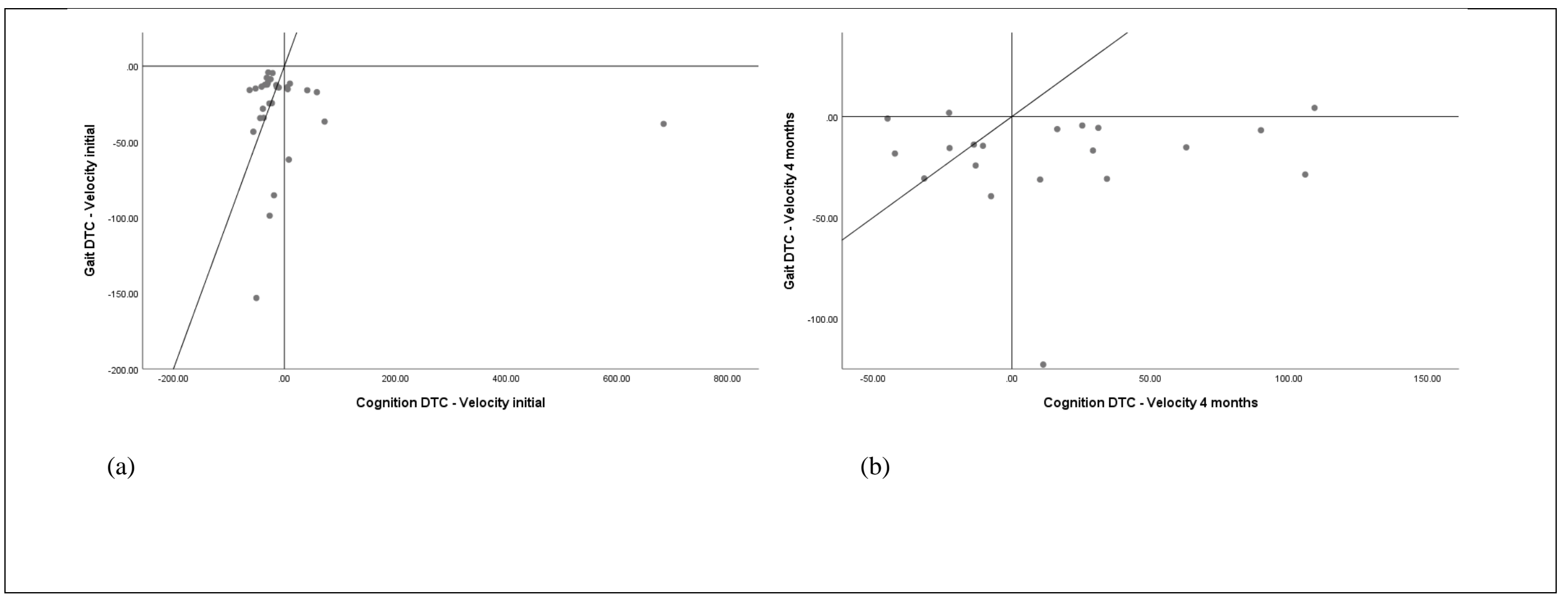

